\title{
Candida clinical species identification: molecular and biochemical methods
}

\author{
Ana Rita Costa • Filipe Silva - Mariana Henriques • \\ Joana Azeredo • Rosário Oliveira • Alberta Faustino
}

Received: 24 September 2009 / Accepted: 27 November 2009 / Published online: 16 February 2010

(C) Springer-Verlag and the University of Milan 2010

\begin{abstract}
In the last decade, the number and diversity of nosocomial Candida infections has increased significantly, resulting in an emergent need for rapid and accurate methods for Candida identification. Therefore, the aim of this study was to evaluate the performance of three biochemical systems (Auxacolor, ID32C, and Vitek 2 YST) for the identification of Candida species, comparing them with molecular identification (polymerase chain reaction and gel agarose electrophoresis). These methods were used to assess Candida spp. (229 clinical isolates) prevalence and distribution among clinical specimens. The biochemical methods with higher percentages of correct identification were Vitek 2 YST (79.6\%) and Auxacolor (78.6\%). However, overall the biochemical methods assayed differed from the molecular identification. Thus, due to their rapid and precise identification, molecular methods are promising techniques for Candida species identification in clinical laboratories. Candida albicans and Non Candida albicans Candida species had a similar prevalence (50.4 and 49.6\%, respectively), corroborating the epidemiological shift observed for these pathogens in the recent years.
\end{abstract}

Keywords Candida species - Discriminating potential . PCR · Vitek 2 YST · Auxacolor · ID32C

\footnotetext{
A. R. Costa $\cdot$ M. Henriques $(\bowtie) \cdot J$. Azeredo $\cdot$ R. Oliveira

A. Faustino

Institute for Biotechnology and Bioengineering,

Centre of Biological Engineering, Universidade do Minho,

4710-057 Braga, Portugal

e-mail: mcrh@deb.uminho.pt

F. Silva

Hospital de S. Marcos,

Largo Carlos Amarante,

4701-965 Braga, Portugal
}

\section{Introduction}

In the last two decades, the incidence of Candida infections, associated with high morbidity and mortality (Goodrich et al. 1991; Beck-Sagué and Jarvis 1993; Karlowsky et al. 1997; Nucci et al. 1997), has increased remarkably (Warren and Hazen 1995; Wingard 1995; Ribeiro et al. 2004). Although Candida albicans is the most prevalent species (Fridkin and Jarvis 1996), an epidemiological shift of Candida pathogens has been recently denoted by the increasing number of infections caused by non-Candida albicans Candida (NCAC) species (Hazen 1995; Jarvis 1995; Fridkin and Jarvis 1996; Nauyen et al. 1996). This increased species diversity and incidence of infections resulted in the need for rapid and accurate methods for Candida identification (Verweij et al. 1999; Wadlin et al. 1999; Hsu et al. 2003; Crocco et al. 2004). This will have a decisive contribution in the evolution of treatment by adequate antifungal selection, and allow the epidemiologic study of colonization and infection in hospitals (Campbell et al. 1999; Verweij et al. 1999; Ribeiro et al. 2004). Several commercial systems have been developed and compared for yeast identification (Fenn et al. 1994; Gutierrez et al. 1994; Fricker-Hidalgo et al. 1995; Verweij et al. 1999; Hata et al. 2007), such as the manual Auxacolor (colorimetric) and ID32C (turbidimetric) systems, and the automated Vitek 2 YST (colorimetric) system (Campbell et al. 1999; Verweij et al. 1999). Table 1 shows a brief review of the comparison of the methods found in the literature.

Misidentifications between some Candida species are frequently observed, particularly between $C$. dubliniensis and C. albicans (Abaci et al. 2008). To distinguish between them, methods such as the latex agglutination test can be used (Kurzai et al. 1999; Marot-Leblond et al. 2006).

However, in spite of the advances in biochemical commercial systems, so far they do not allow for the rapid diagnosis of 
Table 1 Brief review of method comparisons in the literature

\begin{tabular}{|c|c|c|c|}
\hline Authors & Year & Compared methods & Conclusions \\
\hline Fenn et al. & 1994 & $\begin{array}{l}\text { Vitek Yeast Biochemical Card (YBC); API } \\
\text { 20C }\end{array}$ & $\begin{array}{l}\text { Vitek YBC compared favourably with the API } 20 \mathrm{C} \text { in the } \\
\text { identification of common yeasts. } \\
\text { However, Vitek demonstrated problems in the identification of } \\
\text { C. tropicalis, C. krusei, Trichosporon spp., and some } \\
\text { Cryptococcus spp. }\end{array}$ \\
\hline Fricker-Hidalgo et al. & 1995 & Auxacolor; ID 32C & $\begin{array}{l}\text { Auxacolor was found to be reliable when performed in } \\
\text { conjunction with morphological tests. Furthermore, Auxacolor } \\
\text { provided faster results than ID } 32 \mathrm{C} \text {. }\end{array}$ \\
\hline Verweij et al. & 1999 & $\begin{array}{l}\text { Vitek; ID 32C; Api 20C AUX; Yeast Star; } \\
\text { Auxacolor; RapID Yeast Plus system; Api } \\
\text { Candida; Conventional tests }\end{array}$ & $\begin{array}{l}\text { Auxacolor and Api Candida appeared to be the most useful } \\
\text { systems for identification of germ tube negative yeasts. }\end{array}$ \\
\hline Wadlin et al. & 1999 & $\begin{array}{l}\text { RapID Yeast Plus System; API 20C Aux; } \\
\text { Vitek Yeast Biochemical Card, microscopic } \\
\text { morphologic reference method }\end{array}$ & $\begin{array}{l}\text { The RapID Yeast Plus System was significantly better than the } \\
\text { other methods. } \\
\text { There was no significant difference between results obtained } \\
\text { with API 20C Aux and Vitek Yeast Biochemical Card. }\end{array}$ \\
\hline Campbell et al. & 1999 & API Candida; Auxacolor & $\begin{array}{l}\text { The methods had similar percentages of correct identification. } \\
\text { However, the API Candida system required supplemental } \\
\text { biochemical tests or morphological assessment to obtain the } \\
\text { correct identification, and gave more incorrect identifications. }\end{array}$ \\
\hline Kanbe $\mathrm{T}$ et al. & 2003 & $\begin{array}{l}\text { PCR amplification; Conventional } \\
\text { identification techniques }\end{array}$ & $\begin{array}{l}\text { The results of identification of clinical samples based on the } \\
\text { PCR amplification coincided with those of conventional } \\
\text { identification techniques. }\end{array}$ \\
\hline Liguori et al. & 2007 & $\begin{array}{l}\text { Multiplex PCR assay; Routine phenotypic } \\
\text { culture identification }\end{array}$ & $\begin{array}{l}\text { The multiplex PCR assay provides a rapid alternative to the } \\
\text { conventional culture based technique for the identification and } \\
\text { speciation of the most frequently isolated Candida species. }\end{array}$ \\
\hline
\end{tabular}

invasive fungal infections (Goodwin et al. 1992; Hazen 1995; Espinel-Ingroff et al. 1998), leading to a late introduction of the specific antifungal therapy (Goodwin et al. 1992; Hazen 1995; Espinel-Ingroff et al. 1998; Hsu et al. 2003; Huang et al. 2006). In this sense, molecular biology techniques, such as PCR, might be more accurate and efficient, due to their reproducibility, high specificity, and sensitivity (Hidalgo et al. 2000; Kanbe et al. 2002, 2003; Hsu et al. 2003), allowing same day identification. Nevertheless, their lack of standardization for Candida species identification, as well as the extra costs associated and the reliance on Candida cultures that results in a considerable delay in comparison to direct specimen detection, may limit its use.

The aim of this study, carried out at the Service of Clinical Pathology of Hospital de São Marcos (HSM), was to evaluate the performance of the biochemical systems Auxacolor, ID32C, and Vitek 2 YST for the identification of Candida species, comparing to a molecular identification, and to assess Candida spp. prevalence and distribution among clinical specimens.

\section{Materials and methods}

Clinical isolates and culture conditions A total of 229 isolates were randomly isolated from clinical samples (sputum/bronchial wash/bronchoalveolar lavage, vaginal swab, blood culture, catheter tip and urine, among others) between December 2005 and March 2007, in HSM. The clinical isolates were kept in Brain Heart Infusion (BHI, $37 \mathrm{~g} / \mathrm{l}$; Bio-Rad, Marnes-la-Coquette, France) with 10\% glycerol (Vaz Pereira, Lisbon, Portugal), at $-70^{\circ} \mathrm{C}$. Prior to testing, isolates were retrieved from storage and subcultured, for 24 to $48 \mathrm{~h}$, on plates of Columbia sheep blood agar (bioMérieux, Lyon, France).

Reference strains For quality control, ATCC strains were used: Candida albicans ATCC 90028, C. albicans ATCC 14053, Candida glabrata ATCC 2001, Candida tropicalis ATCC 750, Candida parapsilosis ATCC 22019 and Candida krusei ATCC 6258 (MicroBiologics, Saint Cloud, MN, USA); and a Candida dubliniensis strain provided by Biognóstica from United Kingdom National External Quality Assessment Service. These strains were maintained and grown as described for clinical isolates.

Biochemical identification

Auxacolor system The yeast identification procedures were performed according to the manufacturer's instructions (Bio-Rad). The results were read after incubation for $24 \mathrm{~h}$ 
and $48 \mathrm{~h}$, and identifications were made by referring to the list of numerical profiles provided by the manufacturer.

ID32C system All tests were performed according to the manufacturer's instructions (bioMérieux). The results were read automatically after incubation for 24 and $48 \mathrm{~h}$ using the mini API system (bioMérieux).

Vitek 2 YST system The yeast identification procedures were performed according to the manufacturer's instructions (bioMérieux). Cards were automatically read, and after approximately $18 \mathrm{~h}$ a final identification was obtained using the Vitek 2 database.

Latex aglutination test Bichro-Dubli Fumouze latex agglutination test (Fumouze Diagnostics, Levallois-Perret Cedex, France) was performed to identify $C$. dubliniensis strains. This test is based on the coagglutination of $C$. dubliniensis blastoconidia with blue latex particles coated with a monoclonal antibody, allowing the specific detection of the $C$. dubliniensis cell-surface antigen. All tests were performed according to the manufacturer's instructions.

Molecular identification

DNA purification A $100 \mu$ l yeast suspension was prepared in aqueous saline solution $0.45 \%(\mathrm{w} / \mathrm{v}) \mathrm{NaCl}$ with a turbidity equivalent to $2.0 \mathrm{McF}$ arland. DNA was extracted, isolated and purified according to the protocol of Magna Pure LC DNA Isolation Kit III (Roche Applied Science, Amadora, Portugal). Purified DNA was preserved at $-20^{\circ} \mathrm{C}$.

Nested PCR DNA samples were amplified in a reaction mixture $(50 \mu \mathrm{l})$ that contained $5 \mu \mathrm{l}$ genomic DNA, $17 \mu \mathrm{l}$ double distilled water $\left(\mathrm{ddH}_{2} \mathrm{O}\right.$; Roche Applied Science), $1.5 \mu \mathrm{l}$ of each degenerated primer (Table 2) targeting Candida DNA topoisomerase II gene, which were chosen

Table 2 Primers used for PCR amplification, oligonuclotide sequences and fragment size

\begin{tabular}{|c|c|c|c|}
\hline Primer and target species & Name & Sequence $\left(5^{\prime}-3^{\prime}\right)$ & Amplified fragment size (bp) \\
\hline Degenerated primers & $\begin{array}{l}\text { CDF28 } \\
\text { CDR148 }\end{array}$ & $\begin{array}{l}\text { GGTGGWMGDAAYGGDTWYGGYGC } \\
\text { CCRTCNTGATCYTGATCBGYCAT }\end{array}$ & 1200 \\
\hline \multicolumn{4}{|l|}{ Specific primers } \\
\hline Candida albicans & $\begin{array}{l}\text { CABF59 } \\
\text { CABR110 } \\
\text { CADBR125 }\end{array}$ & $\begin{array}{l}\text { TTGAACATCTCCAGTTTCAAAGGT } \\
\text { GTTGGCGTTGGCAATAGCTCTG } \\
\text { AGCTAAATTCATAGCAGAAAGC }\end{array}$ & $\begin{array}{l}515 \\
665\end{array}$ \\
\hline Candida dubliniensis & $\begin{array}{l}\text { CDBF28 } \\
\text { CDBR110 } \\
\text { CADBR125 }\end{array}$ & $\begin{array}{l}\text { AAATGGGTTTGGTGCCAAATTA } \\
\text { GTTGGCATTGGCAATAGCTCTA } \\
\text { AGCTAAATTCATAGCAGAAAGC }\end{array}$ & $\begin{array}{l}816 \\
966\end{array}$ \\
\hline Candida tropicalis I & $\begin{array}{l}\text { CTPIF36 } \\
\text { CTPIR68 } \\
\text { CTPIR121 }\end{array}$ & $\begin{array}{l}\text { GTTGTACAAGCAGACATGGACTG } \\
\text { CAAGGTGCCGTCTTCGGCTAAT } \\
\text { TCAAGGTACAGTTATGGCCAAGTT }\end{array}$ & $\begin{array}{l}318 \\
853\end{array}$ \\
\hline Candida tropicalis $\mathrm{II}^{*}$ & $\begin{array}{l}\text { CTPIIF36 } \\
\text { CTPII60 } \\
\text { CTPIIR121 }\end{array}$ & $\begin{array}{l}\text { CTGGGAAATTATATAAGCAAGTT } \\
\text { CTTGAGATACTCAATCTTTTATC } \\
\text { TCAATGTACAATTATGACCGAGTT }\end{array}$ & $\begin{array}{l}246 \\
860\end{array}$ \\
\hline Candida parapsilosis I & $\begin{array}{l}\text { CPPIF41 } \\
\text { CPPIR61 } \\
\text { CPPIR122 }\end{array}$ & $\begin{array}{l}\text { TGACAATATGACAAAGGTTGGTA } \\
\text { ACTTTTAAAACTGTTAACCGA } \\
\text { TGTCAAGATCAACGTACATTTAGT }\end{array}$ & $\begin{array}{l}228 \\
837\end{array}$ \\
\hline Candida parapsilosis II $^{\mathrm{a}}$ & $\begin{array}{l}\text { CPPIIF41 } \\
\text { CPPIIR69 } \\
\text { CPPIIR122 }\end{array}$ & $\begin{array}{l}\text { GGACAACATGACAAAAGTCGGCA } \\
\text { TTGTGGTGTAATTCTTGGGAG } \\
\text { GGTAAGGATCAAAGTGCACTTTA }\end{array}$ & $\begin{array}{l}310 \\
837\end{array}$ \\
\hline Candida krusei & $\begin{array}{l}\text { CKSF35 } \\
\text { CKSR57 } \\
\text { CKSR110 }\end{array}$ & $\begin{array}{l}\text { GAGCCACGGTAAAGAATACACA } \\
\text { TTTAAAGTGACCCGGATACC } \\
\text { TTTCTCTGGCAATTCCAATCG }\end{array}$ & $\begin{array}{l}227 \\
756\end{array}$ \\
\hline Candida glabrata & $\begin{array}{l}\text { CGBF35 } \\
\text { CGBR77 } \\
\text { CGBR103 }\end{array}$ & $\begin{array}{l}\text { CCCAAAAATGGCCGTAAGTATG } \\
\text { CTGCTTGAAAGAAATATCGGAGAC } \\
\text { ATAGTCGCTACTAATATCACACC }\end{array}$ & $\begin{array}{l}419 \\
674\end{array}$ \\
\hline
\end{tabular}

${ }^{a}$ These species have two distinct genotypes in the DNA topoisomerase gene ${ }^{12}$ 
according to Kanbe et al. (2002), and $25 \mu$ l PCR Master Mix (Roche Applied Science). The PCR was performed in a thermocycler (T1 Model; Biometra, Goettingen, Germany) with the following cycle parameters: preheating at $94^{\circ} \mathrm{C}$ for $2 \mathrm{~min}, 40$ cycles at $94^{\circ} \mathrm{C}$ for $30 \mathrm{~s}, 55^{\circ} \mathrm{C}$ for $20 \mathrm{~s}$, and $72^{\circ} \mathrm{C}$ for $90 \mathrm{~s}$. These PCR products were further amplified by species specific primers (Table 2), also targeting Candida DNA topoisomerase II gene (Kanbe et

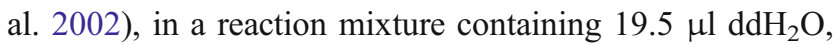
$1.5 \mu \mathrm{l}$ of each species specific primers, $25 \mu$ l PCR Master Mix, and $1 \mu$ DNA template. The PCR thermocycler parameters were the same as described above.

Agarose gel electrophoresis Detection of PCR products was performed by electrophoresis (MiniRun GE-100; Bioer, Tokyo, Japan) on a $1.2 \%$ agarose (QA-Agarose TM; MP Biomedicals, Illkirch, France) gel prepared in 0.5X Tris-Borate-EDTA (TBE; Severn Biotech, Worcestershire, UK), at $100 \mathrm{~V}$ for $35 \mathrm{~min}$ in TBE. Gels were stained with ethidium bromide $(10 \mathrm{mg} / \mathrm{ml}$; Molecular Sigma Biology, Sintra, Portugal) for $20 \mathrm{~min}$, and destained in TBE for $10 \mathrm{~min}$. DNA bands were visualized with a UV transilluminator (Model TM-15E Chromato-Vue ${ }^{\circledR}$; UVP, Cambridge, UK) and photographed. PCR product band size was determined by comparison with a 100 bp DNA ladder (Zymo Research, Orange, CA, USA) ran in the same gel.

Methodology for the analysis of the identification results The biochemical systems of identification were evaluated by comparison with the molecular method (assumed as the reference). Since only the specific primers for C. albicans, C. parapsilosis, C. tropicalis, C. glabrata, C. krusei, and C. dubliniensis were acquired, just 196 isolates were compared. Biochemical identification was understood as: correct when identical to the molecular results; incomplete when it gave more than one possibility of identification (including the correct); incorrect when different from the molecular results; and unidentified when the test gave no identification at all.

Statistical analysis Data from Candida species identification were statistically analyzed with Statistical Package for Social Sciences (SPSS), using the Cochran's Q and McNemar tests with a confidence level of $95 \%$.

\section{Results}

Biochemical and molecular identification

Table 3 summarizes the identification results obtained by the biochemical methods for Candida species, in compar- ison with the molecular identification. The reference strains were correctly identified by all methods, except for $C$. glabrata 2001 and C. krusei 6258 with Auxacolor and $C$. krusei 6258 with Vitek 2 YST, where incomplete identifications were achieved. For the clinical isolates, C. parapsilosis strains were the species most correctly identified by the biochemical methods, while C. glabrata and C. krusei were the species with lower levels of correct identification.

Overall, Vitek 2 YST and Auxacolor (48 h incubation) gave the higher percentages of correct identification (79.6 and $78.6 \%$, respectively).

Results of the biochemical and molecular identification were firstly statistically analyzed with the Cochran's Q test. As the significance value $(P=0.000)$ indicated significant differences among the methods, their responses were subsequently analyzed with the McNemar test. It was possible to verify that ID $32 \mathrm{C}$ results diverged significantly from the other biochemical methods, being the method with worst results for Candida species identification. Furthermore, it was observed that the incubation time is an important aspect for the Auxacolor method, where significantly better results are achieved after $48 \mathrm{~h}$ incubation.

Results from biochemical methods were also compared with molecular identification, as shown in Table 4. All the biochemical methods provided significantly divergent results from molecular identification, with the exception of Auxacolor ( $48 \mathrm{~h}$ incubation) and ID32C (24 h incubation) for C. parapsilosis.

\section{Latex agglutination test}

The agglutination test, performed for strains identified as C. albicans or C. dubliniensis by biochemical methods, provided a positive result for one strain, identified as C. dubliniensis by molecular methods, indicating its accuracy.

Prevalence and distribution of Candida species

Figure 1 shows the prevalence and distribution of Candida species among clinical specimens. Candida albicans was the most prevalent species $(50.4 \%)$, followed by $C$. parapsilosis (13.9\%), C. tropicalis (10.5\%), C. glabrata (9.1\%), C. krusei $(0.9 \%)$, C. dubliniensis $(0.4 \%)$ and other unidentified Candida species (14.8\%). Candida species were more frequently isolated from clinical specimens of urine $(38.9 \%)$, sputum/bronchial wash/bronchoalveolar lavage $(24.9 \%)$, and vaginal swabs $(11.4 \%)$. The second was also the specimen where a major diversity of species was encountered. Indeed, the only strain of $C$. dubliniensis and the two strains of $C$. krusei identified were isolated from sputum/bronchial wash/bronchoalveolar lavage. It should also be noted that $C$. glabrata was isolated in higher 
Table 3 Results of the evaluation of 196 strains using the Auxacolor, ID 32C, and Vitek 2 YST systems, assuming the molecular method as reference

\begin{tabular}{|c|c|c|c|c|c|}
\hline \multirow[t]{2}{*}{ Species } & \multirow[t]{2}{*}{ System and ncubation time (h) } & \multicolumn{4}{|c|}{ Isolates with the following identification (\%) } \\
\hline & & Correct & Incomplete & Incorrect & Unidentified \\
\hline \multirow[t]{7}{*}{ Candida albicans $(n=116)$} & Auxacolor & & & & \\
\hline & 24 & 82.8 & 0.9 & 2.6 & 13.8 \\
\hline & 48 & 92.2 & 0.9 & 2.6 & 4.3 \\
\hline & ID32C & & & & \\
\hline & 24 & 68.1 & 0.9 & 0.9 & 30.2 \\
\hline & 48 & 69.0 & 1.7 & 0.0 & 29.3 \\
\hline & Vitek 2 YST & 87.1 & 7.8 & 3.4 & 1.7 \\
\hline \multirow[t]{7}{*}{ Candida parapsilosis $(n=32)$} & Auxacolor & & & & \\
\hline & 24 & 62.5 & 9.4 & 21.9 & 6.3 \\
\hline & 48 & 93.8 & 3.1 & 0.0 & 3.1 \\
\hline & ID32C & & & & \\
\hline & 24 & 84.4 & 0.0 & 0.0 & 15.6 \\
\hline & 48 & 75.0 & 0.0 & 0.0 & 25.0 \\
\hline & Vitek 2 YST & 78.1 & 15.6 & 3.1 & 3.1 \\
\hline \multirow[t]{7}{*}{ Candida tropicalis $(n=24)$} & Auxacolor & & & & \\
\hline & 24 & 58.3 & 4.2 & 12.5 & 25 \\
\hline & 48 & 58.3 & 4.2 & 8.3 & 29.2 \\
\hline & ID32C & & & & \\
\hline & 24 & 50.0 & 8.3 & 4.2 & 37.5 \\
\hline & 48 & 66.7 & 0.0 & 4.2 & 29.2 \\
\hline & Vitek 2 YST & 75.0 & 0.0 & 4.2 & 20.8 \\
\hline \multirow[t]{7}{*}{ Candida glabrata $(n=21)$} & Auxacolor & & & & \\
\hline & 24 & 4.8 & 90.5 & 4.8 & 0.0 \\
\hline & 48 & 9.5 & 76.2 & 4.8 & 9.5 \\
\hline & ID32C & & & & \\
\hline & 24 & 42.9 & 0.0 & 0.0 & 57.1 \\
\hline & 48 & 52.4 & 0.0 & 0.0 & 47.6 \\
\hline & Vitek 2 YST & 52.4 & 14.3 & 4.8 & 28.6 \\
\hline \multirow[t]{7}{*}{ Candida krusei $(n=2)$} & Auxacolor & & & & \\
\hline & 24 & 0.0 & 100 & 0.0 & 0.0 \\
\hline & 48 & 0.0 & 100 & 0.0 & 0.0 \\
\hline & ID32C & & & & \\
\hline & 24 & 0.0 & 100 & 0.0 & 0.0 \\
\hline & 48 & 0.0 & 100 & 0.0 & 0.0 \\
\hline & Vitek 2 YST & 0.0 & 50.0 & 0.0 & 50.0 \\
\hline \multirow[t]{7}{*}{ Candida dubliniensis $(n=1)$} & Auxacolor & & & & \\
\hline & 24 & 100 & 0.0 & 0.0 & 0.0 \\
\hline & 48 & 100 & 0.0 & 0.0 & 0.0 \\
\hline & ID32C & & & & \\
\hline & 24 & 0.0 & 0.0 & 100 & 0.0 \\
\hline & 48 & 0.0 & 0.0 & 100 & 0.0 \\
\hline & Vitek 2 YST & 100 & 0.0 & 0.0 & 0.0 \\
\hline \multirow[t]{7}{*}{ Candida (total) $(n=196)$} & Auxacolor & & & & \\
\hline & 24 & 67.3 & 13.3 & 7.1 & 12.2 \\
\hline & 48 & 78.6 & 10.7 & 3.1 & 7.7 \\
\hline & ID32C & & & & \\
\hline & 24 & 64.8 & 2.6 & 1.5 & 31.1 \\
\hline & 48 & 66.8 & 2.0 & 1.0 & 30.1 \\
\hline & Vitek 2 YST & 79.6 & 9.2 & 3.6 & 7.7 \\
\hline
\end{tabular}


Table 4 Significance values $(P)$ obtained from the comparison between the results of biochemical systems and the molecular method

\begin{tabular}{llllll}
\hline System and incubation time & \multicolumn{2}{l}{ Significance $(P)$} & & \\
\cline { 2 - 6 } & Candida albicans & Candida parapsilosis & Candida tropicalis & Candida glabrata & Candida (overall) \\
\hline Auxacolor 24 h & 0.000 & 0.000 & 0.002 & 0.000 & 0.000 \\
Auxacolor 48 h & 0.004 & 0.500 & 0.002 & 0.000 & 0.000 \\
ID32C 24 h & 0.000 & 0.063 & 0.000 & 0.000 & 0.000 \\
ID32C 48 h & 0.000 & 0.008 & 0.008 & 0.002 & 0.000 \\
Vitek 2 YST & 0.000 & 0.016 & 0.031 & 0.002 & 0.000 \\
\hline
\end{tabular}

numbers from vaginal swabs, and $C$. parapsilosis from the group identified as "Other".

\section{Discussion}

In this work, three biochemical systems were evaluated (Auxacolor, ID32C, and Vitek 2 YST) in comparison to molecular identification. Considerable differences were noted between the biochemical and molecular identification, especially for ID32C, which was demonstrated to be the less accurate system. These divergences were observed for all Candida species, with the exception of $C$. parapsilosis for Auxacolor (48 h incubation) and ID32C (24 h incubation). Indeed, this species was the easiest to identify by biochemical methods, followed by $C$. albicans, whose levels of correct identification were high for Auxacolor and
Vitek 2 YST. On the other hand, C. glabrata and C. krusei, usually associated with high levels of antifungal resistance, posed the greatest identification problems. For C. krusei it is not possible to reach any conclusion since the number of isolates was too low (two). As for C. glabrata, it could be said that it is the hardest species to identify, especially by Auxacolor whose higher percentages of incomplete identification should be emphasized. Candida tropicalis, although not with the extension of C. glabrata, was also difficult to identify with ID32C and Auxacolor.

Regarding $C$. dubliniensis, since the number of strains identified (one) did not allow a statistical analysis of its identification, it can merely be stated that Vitek 2 YST and Auxacolor correctly identified the isolate, and ID32C identified it, incorrectly, as $C$. albicans. Indeed, the distinction between these two species is problematic. Therefore, a latex agglutination test was performed, which
Fig. 1 Distribution of Candida species among clinical specimens

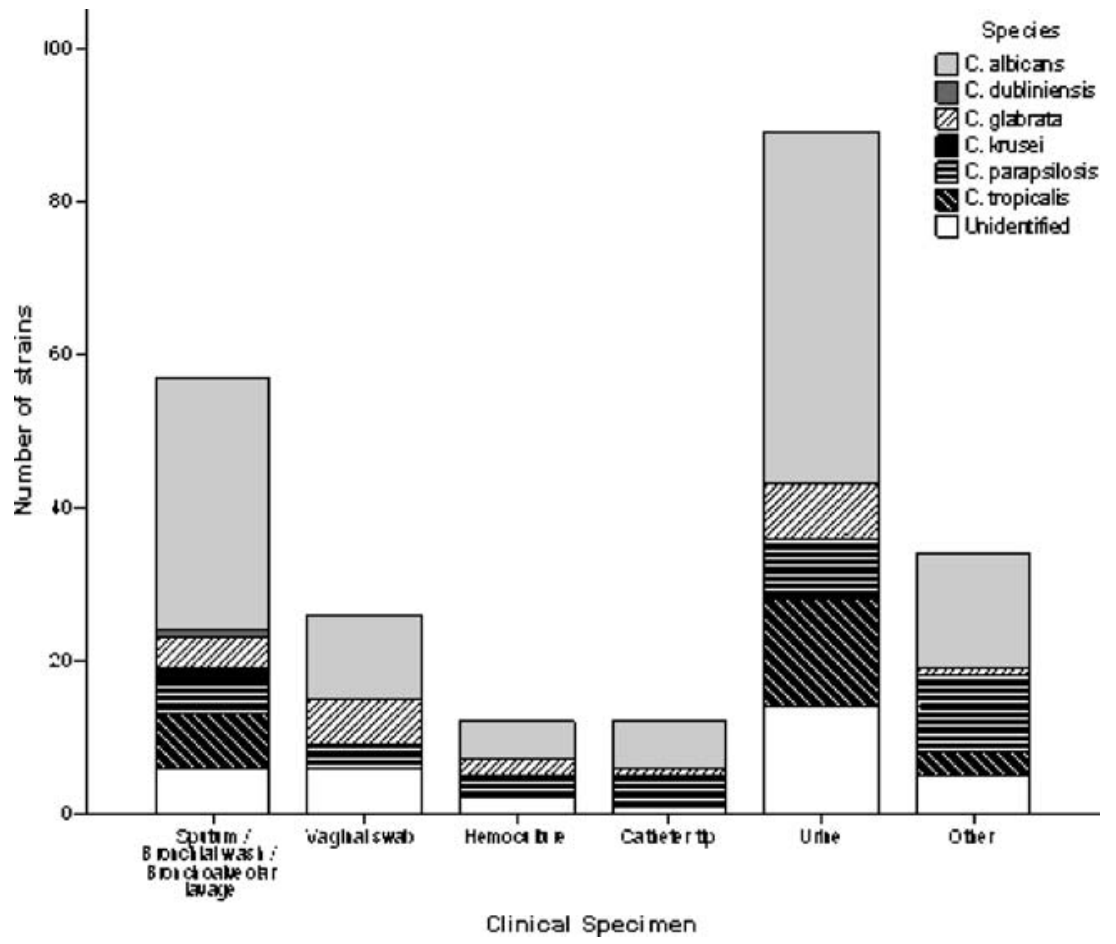


correctly identified the $C$. dubliniensis isolate. These results agree with previous studies (Marot-Leblond et al. 2006; Sahand et al. 2006) and indicate the accuracy of this test for discrimination between $C$. dubliniensis and C. albicans.

It should be noted that the levels of correct identification obtained in this study for the biochemical methods were lower than reported in previous studies (Loïez et al. 2006; Hata et al. 2007; Sheppard et al. 1998). This may be due, contrary to other studies, to the absence of supplementary tests, which are very time consuming and therefore disagree with the aim of this work that consisted in finding an expeditious methodology for Candida species identification.

In this work, we also compared the 24 and $48 \mathrm{~h}$ incubation times for Auxacolor and ID32C. Significant differences were found only for Auxacolor, showing better identification results for a $48 \mathrm{~h}$ incubation, which is in accordance with a previous study (Loïez et al. 2006).

In the present work, the prevalence and distribution of Candida species among clinical specimens was, for the first time, evaluated in HSM. The results obtained are in accordance with previous studies (Krcmery and Barnes 2002; Fleck et al. 2007), with C. albicans being the most prevalent species. However, NCAC levels are similar, corroborating the values in literature that denote the epidemiological shift of Candida pathogens perceived in the last years (Hazen 1995; Jarvis 1995).

\section{References}

Abaci Ö, Halki-Huztan A, Ates M (2008) Specific identification of Candida albicans and Candida dubliniensis by PCR using species-specific primers. Ann Microbiol 58:325-331

Beck-Sagué C, Jarvis WR (1993) Secular trends in the epidemiology of nosocomial fungal infections in the United States, 1980-1990. Nosocomial Infections Surveillance System. J Infect Dis 167:1247-1251

Campbell CK, Davey KG, Holmes AD, Szekely A, Warnock DW (1999) Comparison of the API Candida system with Auxacolor system for identification of common yeast pathogens. J Clin Microbiol 37:821-823

Crocco EI, Souza VM, Mimica LMJ, Muramatu LH, Garcia C, Ruiz LRB, Zaitz C (2004) Identificação de espécies de Candida e susceptibilidade antifúngica in vitro: estudo de 100 pacientes com candidíases superficiais. An Bras Dermatol 79:689-697

Espinel-Ingroff A, Stockman L, Roberts G, Pincus D, Pollack J, Marler J (1998) Comparison of RapID yeast plus system with API 20C system for identification of common, new, and emerging yeast pathogens. J Clin Microbiol 36:883-886

Fenn JP, Segal H, Barland B, Denton D, Whisenant J, Chun H, Christofferson K, Hamilton L, Carroll K (1994) Comparison of updated Vitek yeast biochemical card and API 20C yeast identification systems. J Clin Microbiol 32:1184-1187

Fleck R, Dietz A, Hof H (2007) In vitro susceptibility of Candida species to five antifungal agents in a German university hospital assessed by the reference broth microdilution method and Etest. J Antimicrob Chemother 59:767-771
Fricker-Hidalgo H, Lebeau B, Kervroedan P, Faure O, AmbroiseThomas P, Grillot R (1995) Auxacolor, a new commercial system for yeast identification: evaluation of 182 strains comparatively with ID 32 C. Ann Biol Clin 53:221-225

Fridkin SK, Jarvis WR (1996) Epidemiology of nosocomial fungal infections. Clin Microbiol Rev 9:499-511

Goodrich JM, Reed EC, Mori M, Fisher LD, Skerrett S, Dandliker PS, Klis B, Counts GW, Meyers JD (1991) Clinical features and analysis of risk factors for invasive candidal infection after marrow transplantation. J Infect Dis 164:731-740

Goodwin SD, Fiedler-Kelly J, Grasela TH, Schell WA, Perfect JR (1992) A nationwide survey of clinical laboratory methodologies for fungal infections. J Med Vet Mycol 30:153-160

Gutierrez J, Martin E, Lozano C, Coronilla J, Nogales C (1994) Evaluation of the ATB $32 \mathrm{C}$, automicrobic system and API $20 \mathrm{C}$ using clinical yeast isolates. Ann Biol Clin 50:443-446

Hata DJ, Hall L, Fothergill AW, Larone DH, Wngenack NL (2007) Multicenter evaluation of the new VITEK 2 advanced colorimetric yeast identification card. J Clin Microbiol 45:1087-1092

Hazen KC (1995) New and emerging yeast pathogens. Clin Microbiol Rev 8:462-478

Hidalgo JA, Alangaden GJ, Eliott D, Akins RA, Puklin J, Abrams G, Vazquez JA (2000) Fungal endophthalmitis diagnosis by detection of Candida albicans DNA in intraocular fluid by use of a species-specific polymerase chain reaction assay. J Infect Dis 181:1198-1201

Hsu M-C, Chen K-W, Lo H-J, Chen Y-C, Lião M-H, Lin Y-H, Li S-Y (2003) Species identification of medically important fungi by use of real-time LightCycler PCR. J Med Microbiol 52:10711076

Huang A, Li J-W, Shen Z-Q, Wang X-W, Jin M (2006) Highthroughput identification of clinical pathogenic fungi by hibridization to an oligonucleotide microarray. J Clin Microbiol 44:3299-3305

Jarvis WR (1995) Epidemiology of nosocomial fungal infections, with emphasis on Candida species. Clin Infect Dis 20:1526-1530

Kanbe T, Horii T, Arishima T, Ozeki M, Kikuchi A (2002) PCR-based identification of pathogenic Candida species using primer mixes specific to Candida DNA topoisomerase II genes. Yeast 19:973989

Kanbe T, Arishima T, Horii T, Kikuchi A (2003) Improvements of PCR-based identification targeting the DNA Topoisomerase II gene to determine major species of the opportunistic fungi Candida and Aspergillus fumigatus. Microbiol Immunol 47:631638

Karlowsky JA, Zhanel GG, Klym KA, Hoban DJ, Kabani AM (1997) Candidemia in a Canadian tertiary care hospital from 1976 to 1996. Diagn Microbiol Infect Dis 28:5-9

Krcmery V, Barnes AJ (2002) Non-albicans Candida spp. causing fungaemia: pathogenicity and antifungal resistance. J Hosp Infect $50: 243-260$

Kurzai O, Heinz WJ, Sullivan DJ, Coleman DC, Frosch M, Mühlschlegel FA (1999) Rapid PCR test for discriminating between Candida albicans and Candida dubliniensis isolates using primers derived from the $\mathrm{pH}$-regulated PHR1 and PHR2 genes of $C$. albicans. J Clin Microbiol 37:1587-1590

Liguori G, Lucariello A, Colella G, De Luca A, Marinelli P (2007) Rapid identification of Candida species in oral rinse solutions by PCR. J Clin Pathol 60:1035-1039

Loïez C, Wallet F, Sendid B, Courcol RJ (2006) Evaluation of VITEK 2 colorimetric cards versus fluorimetric cards for identification of yeasts. Diagn Microbiol Infect Dis 56:455-457

Marot-Leblond A, Beucher B, David S, Nail-Billaud S, Robert R (2006) Development and evaluation of a rapid latex agglutination test using a monoclonal antibody to identify Candida dubliniensis colonies. J Clin Microbiol 44:138-142 
Nauyen MH, Peacock JE, Moris AJ, Tanner DC, Nguyen ML, Snydman DR, Wagener MM, Rinaldi MG, Yu VL (1996) The changing face of candidemia: emergence of non-Candida albicans species and antifungal resistance. Am J Med 100:617-623

Nucci M, Spector N, Bueno A, Solza C, Perecmanis T, Bacha PC, Pulcheri W (1997) Risk factors and attributable mortality associated with superinfections in neutropenic patients with cancer. Clin Infect Dis 24:575-579

Ribeiro EL, Guimarães RI, Inácio MCC, Ferreira WM, Cardoso CG, Dias SMS, Naves LF (2004) Aspectos das leveduras de Candida vinculadas as infecções nosocomiais. NewsLab 64:106-124

Sahand IH, Moragues MD, Robert R, Quindós G, Pontón J (2006) Evaluation of Bichro-Dubli Fumouze ${ }^{\circledR}$ to distinguish Candida dubliniensis from Candida albicans. Diagn Microbiol Infect Dis 55:165-167

Sheppard DC, Souza E, Hashmi Z, Robson HG, René P (1998) Evaluation of the Auxacolor system for biochemical identifica- tion of medically important yeasts. J Clin Microbiol 36:37263727

Verweij PE, Breuker IM, Rijs AJ, Meis JF (1999) Comparative study of seven commercial yeast identification systems. J Clin Pathol $52: 271-273$

Wadlin JK, Hanko G, Stewart R, Pape J, Nachamkin I (1999) Comparison of three commercial systems for identification of yeasts commonly isolated in the clinical microbiology laboratory. J Clin Microbiol 37:1967-1970

Warren NG, Hazen KC (1995) Candida, Cryptococcus, and other yeasts of medical importance. In: Murray PR, Baron GJ, Pfaller MA, Tenover FC, Yolken RH (eds) Manual of clinical microbiology, 6th edn. American Society for Microbiology, Washington DC, pp 723-737

Wingard JR (1995) Importance of Candida species other than $C$. albicans as pathogens in oncology patients. Clin Infect Dis $20: 115-125$ 